\title{
Internet-Based Studies
}

\author{
Ulf-Dietrich Reips ${ }^{1,2}$
}

(1) Faculty of Engineering; Faculty of Education and Psychology, Universidad de Deusto, Bilbao, Spain

(2) IKERBASQUE, Basque Foundation for Science, Bilbao, Spain

\section{Ulf-Dietrich Reips}

Email: u.reips@ikerbasque.org

Email: reips@deusto.es

\section{Without Abstract}

\section{Synonyms}

Internet science; iScience; Internet-mediated studies; Web-based studies

\section{Definition}

Internet-based studies are roughly systematized in four categories (Reips, 2006): Internet-based experiments, web surveys and questionnaires, Internet-based assessment, and nonreactive data collection on the Internet. In a wider sense, studies about human activities on the Internet can also be defined as Internet-based studies.

\section{Description}




\section{Beginning}

The first Internet-based studies were conducted in the mid-1990s, shortly after the World Wide Web had been invented at CERN in Geneva (Musch \& Reips, 2000; Reips, 2006). Conducting studies via the Internet is considered a second revolution in behavioral research, after the computer revolution in the late 1960s and early 1970s that brought about many advantages over widely used paper-and-pencil procedures (e.g., automated processes, heightened precision). The Internet revolution in behavioral research added the dimension of interactivity via a worldwide network that resulted in several mostly advantageous characteristics of Internet-based studies (see below).

Examples for studies conducted on the WWW, current and archived, can be viewed at sites like the Web experiment list (http://wexlist.net, Reips \& Lengler, 2005), see Fig. 1, and the Psychological Research on the Net list that is maintained by John Krantz (http://psych.hanover.edu/research/exponnet.html).

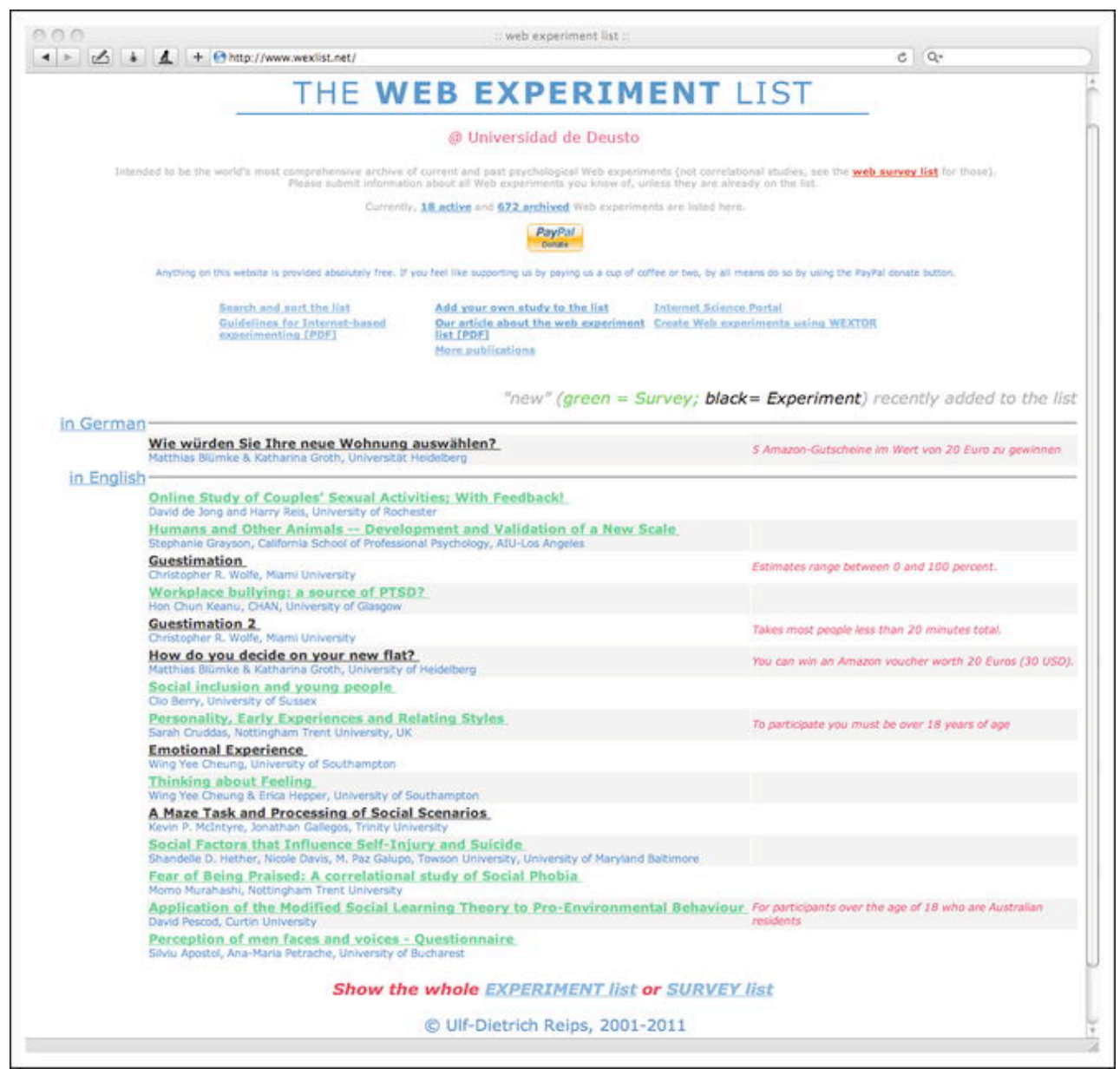

\section{Internet-Based Studies, Fig. 1}

The web experiment list and web survey list 


\section{Characteristics}

Although Internet-based studies have some inherent limitations due to a lack of control and observation of conditions, they also have a number of advantages over lab research (Birnbaum, 2004; Kraut et al., 2004; Reips, 2002; Schmidt, 1997). Some of the chief advantages are that (1) researchers can recruit and study large numbers of participants very quickly; (2) it is possible to collect and access large behavioral data sets, recruit large heterogeneous samples and people with rare characteristics (e.g., people who have had biofeedback training in more than one country or persons suffering from sexsomnia and their peers, Mangan \& Reips, 2007) from locations far away; and (3) the method is more cost-effective in time, space, and labor in comparison with lab research. Compared to paper-and-pencil research, most of the advantages of computer-mediated research apply, for example, process variables ("paradata") that can be recorded (Stieger \& Reips, 2010).

\section{Types}

Internet-based studies are roughly systematized in four categories (Reips, 2006, see Fig. 2): Internet-based experiments (Reips, 2002), web surveys and questionnaires (Dillman \& Bowker, 2001; Dillman, Smyth, \& Christian, 2009), Internet-based assessments (Buchanan, 2001; Buffardi \& Campbell, 2008), and nonreactive data collection on the Internet (Reips \& Garaizar, 2011). Within psychology, most Internet-based research is conducted in the fields of social psychology and cognition (Musch \& Reips, 2000; Reips \& Lengler, 2005). Within behavioral medicine, as judged from an analysis of the articles published in the Journal of Medical Internet Research, the most frequented fields seem to be e-health and e-mental health, in particular depression, obesity/weight management, and smoking cessation. 


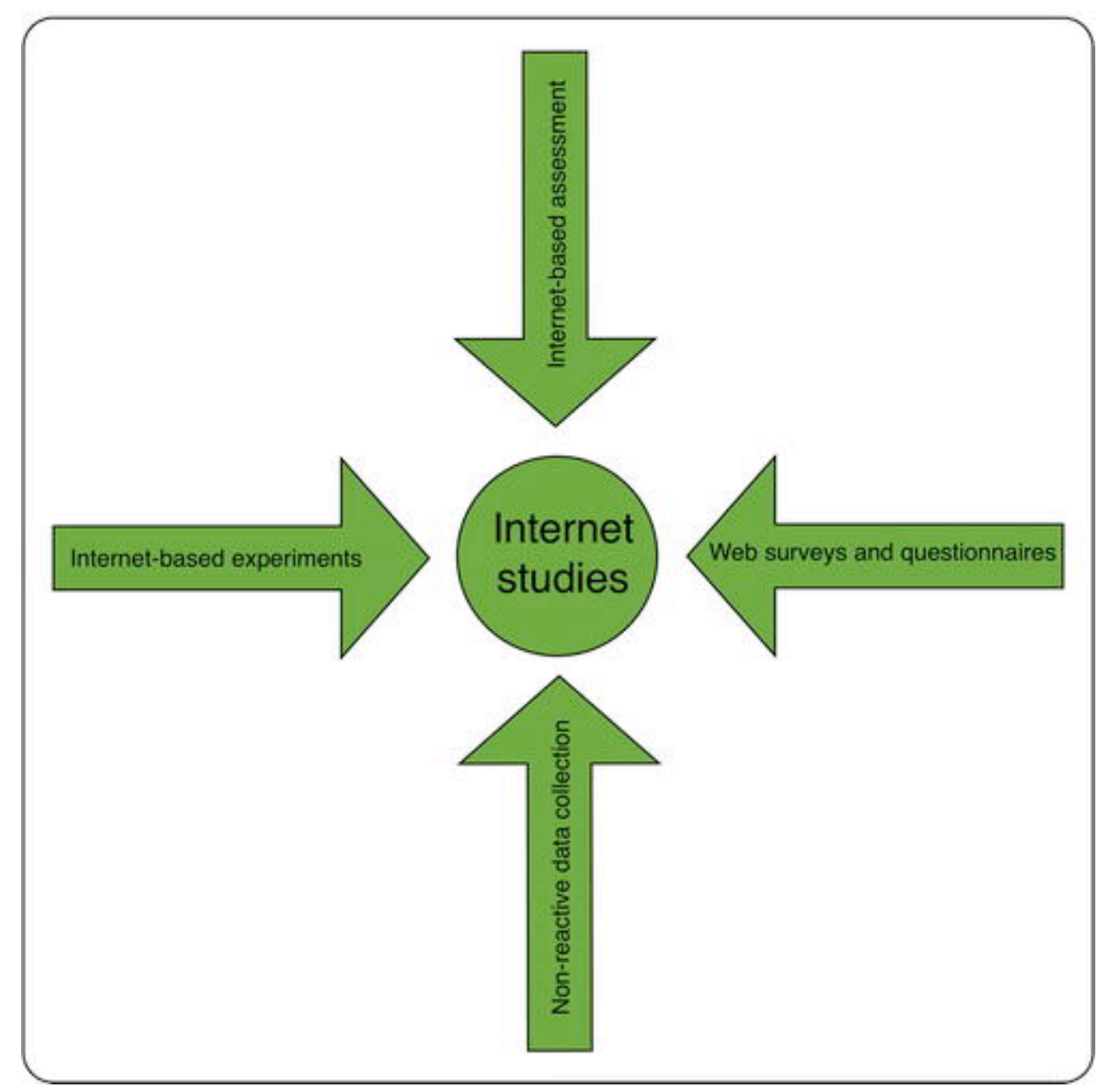

\section{Internet-Based Studies, Fig. 2}

Types of Internet-based studies

In a wider sense, studies about human activities on the Internet (e.g., accessing Internet support groups, online dating) can also be defined as Internet-based studies (e.g., Eysenbach, Powell, Englesakis, Rizo, \& Stern, 2004; Whitty \& Buchanan, 2010).

Recently, the advent of social media, that is, highly interactive Internet-based communication platforms, has spurred the interest of researchers. Social networking services like Facebook, Tuenti, Orkut, LinkedIn, Twitter, and Student VZ are seen as vast resources for detailed descriptions of human behavior (Reips \& Garaizar, 2011).

\section{Methods}

For anyone planning to conduct studies via the Internet, it is important to realize that there is a growing body of literature on theoretical insights, empirical results, and practical guidelines that needs to be taken into account when setting up Internet-based data collection. 
Reips (2002) and Reips and Birnbaum (2011) provide guidelines and overviews of techniques, methods, and tools for Internet-based studies. They summarize challenges and solutions in design, security, recruitment, sampling, self-selection, multiple submissions, reactancefree question design, response time measurement, dropout, error estimation, data handling, and data quality. For example, in creating items for a Web questionnaire it is often forgotten to add a neutral option ("please choose") in drop-down menus. Thus, one of the answer options is automatically selected, even if the respondent skips the item. Another pitfall is the higher likelihood for attrition on the web, compared to lab-based studies. Among other methods that have been developed in web methodology and Internet science, Reips (2010) explains the one-item-one-screen (OIOS) design, the seriousness check, subsampling procedures, multiple site entry, and the high hurdle technique and discusses empirical results from investigations into the validity of several of the techniques.

\section{Implications}

Most authors agree that the Internet is a viable option for conducting studies in the behavioral and social sciences (Birnbaum, 2004; Joinson, McKenna, Postmes, \& Reips, 2007; Kraut et al., 2004; Musch \& Reips, 2000; Reips, 2002, 2006). Care should be taken to properly implement an adequate methodology suited for Internet-based studies (Reips, 2002) and consider potentially biasing effects of technology (Schmidt, 2007).

Two important issues for much of human interaction on and with the Internet are: real and perceived privacy as well as trust, for example, in accessing health-related information via the Internet (Buchanan, Joinson, Paine, \& Reips, 2007; Eysenbach et al., 2004). Such information can be accessed more easily via the Internet, in part because it can be found more privately. Threats to privacy on the Internet reduce the willingness to look for information online. Furthermore, people are less likely to search for healthcare information through mechanisms or agencies that they do not trust (Buchanan et al., 2007). For the data quality in Internet-based studies that usually involve self-disclosure perceived, privacy and trust are essential as well (Joinson, Reips, Buchanan, \& Paine Schofield, 2010).

It seems important that authors, reviewers, and editors of articles 
reporting results from Internet-based studies follow the guidelines that were developed in this new field. Scientists in behavioral medicine considering to conduct research via the Internet will thus need to prepare for challenges like more heterogeneous samples, higher nonresponse, and the effects of mode and technologies. Benefits like wider reach, better quality of data from truly voluntary respondents, and a reduced tendency for socially desirable responding, reduced costs, and validated tools for Internet-based research will further increase the use of the new methodology.

\section{Resources}

The following resources are available for researchers who want to conduct Internet-based studies:

- iScience Server (http://iscience.eu/, Fig. 3): A portal for the methodology of Internet-based research

- iScience Maps (http://tweetminer.eu/, Reips \& Garaizar, 2011): A data mining tool for the social media service Twitter

- Questionnaire evaluator (http://iscience.eu/fbchecker/): An interactive web tool to examine questions and questionnaires (in German and English)

- Big 5 (http://webscience.deusto.es/big5/): A self-scoring Big Five personality test ready for use by simply linking it to another online study (in English, German, and Spanish)

- VAS Generator (http://www.vasgenerator.net/, Reips \& Funke, 2008): A tool to create visual analogue scales (VAS) for online studies

- WEXTOR (http://wextor.org, Reips \& Neuhaus, 2002, Fig. 4): A system for conducting web-based experiments 


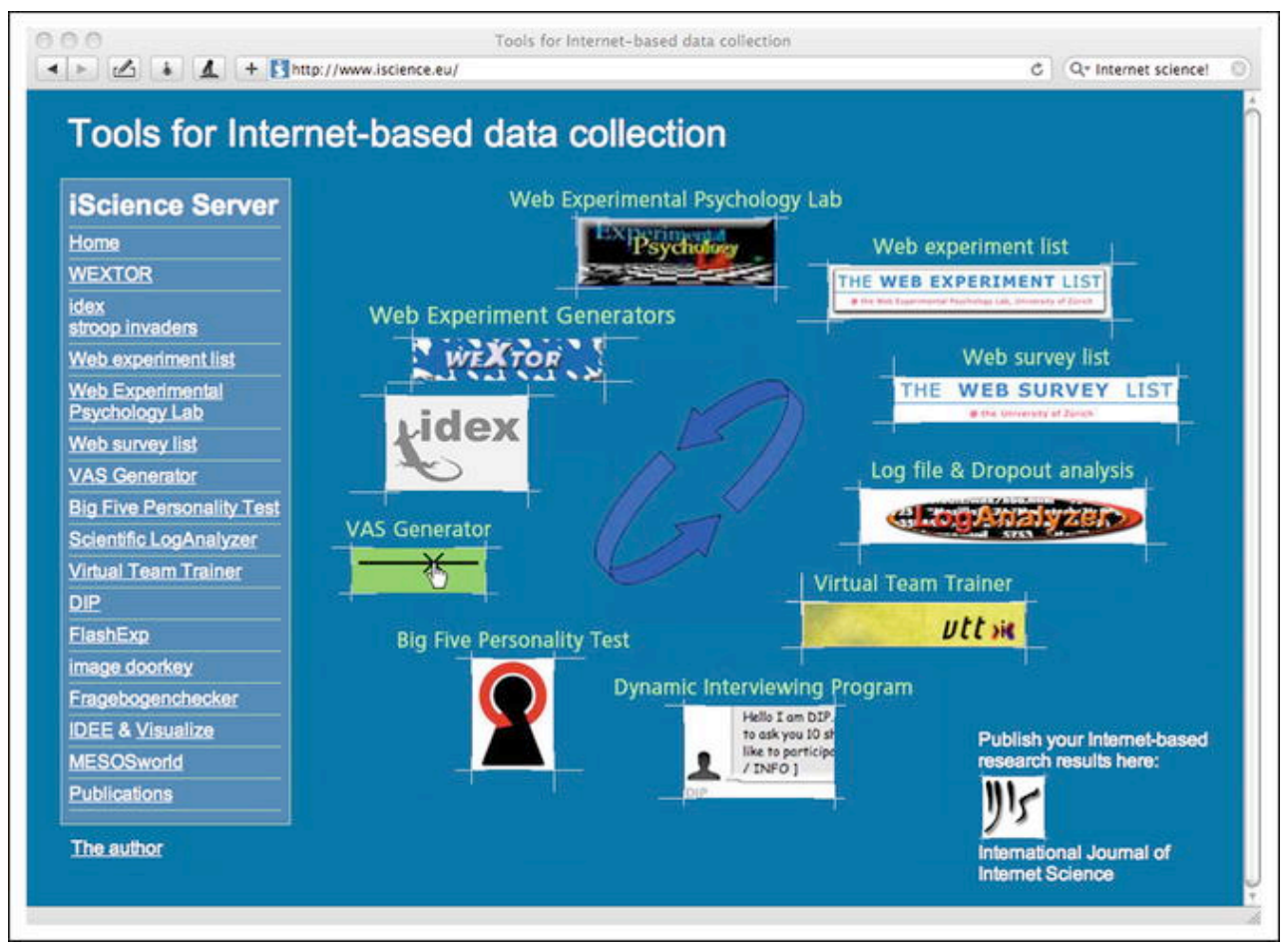

\section{Internet-Based Studies, Fig. 3}

A portal for researchers that links to many tools for Internet-based studies: the iScience Server at http://iscience.eu

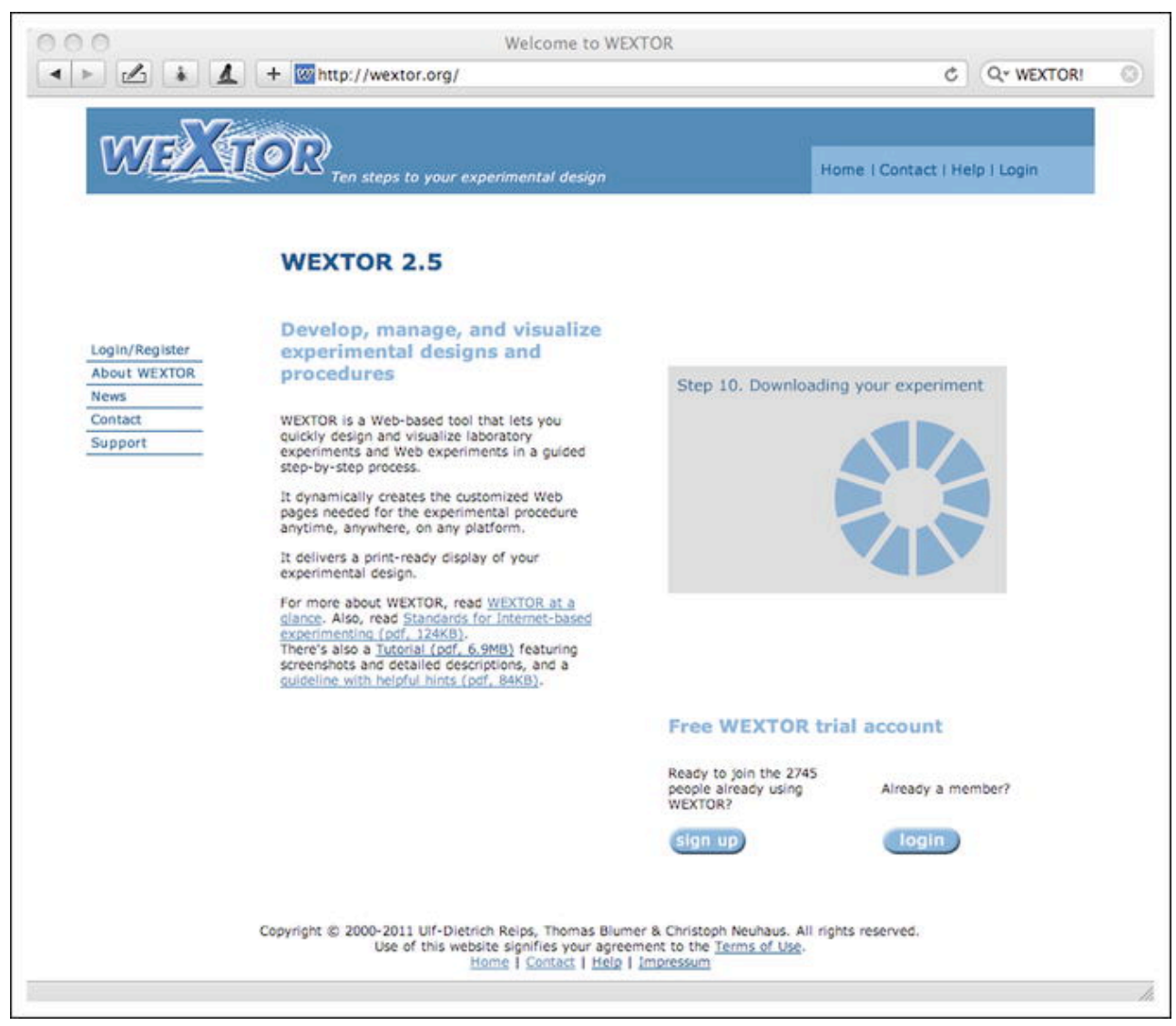

Internet-Based Studies, Fig. 4

WEXTOR, a web service to generate and conduct Internet-based experiments 


\section{References and Readings}

Birnbaum, M. H. (2004). Human research and data collection via the Internet. Annual Review of Psychology, 55, 803-832.

PubMed CrossRef

Buchanan, T. (2001). Online personality assessment. In U.-D. Reips \& M. Bosnjak (Eds.), Dimensions of Internet science (pp. 57-74). Lengerich, Germany: Pabst Science.

Buchanan, T., Joinson, A. N., Paine, C., \& Reips, U.-D. (2007). Looking for medical information on the Internet: Self-disclosure, privacy and trust. He@lth Information on the Internet, 58, 8-9.

Buffardi, L. E., \& Campbell, W. K. (2008). Narcissism and social networking web sites. Personality and Social Psychology Bulletin, 34, 1303-1314.

PubMed CrossRef

Dillman, D. A., \& Bowker, D. (2001). The web questionnaire challenge to survey methodologists. In U.-D. Reips \& M. Bosnjak (Eds.), Dimensions of Internet science (pp. 159177). Lengerich, Germany: Pabst Science.

Dillman, D. A., Smyth, J. D., \& Christian, L. M. (2009). Internet, mail and mixed-mode surveys: The tailored design method (3rd ed.). Hoboken, NJ: Wiley.

Eysenbach, G., Powell, J., Englesakis, M., Rizo, C., \& Stern, A. (2004). Health-related virtual communities and electronic support groups: Systematic review of the effects of online peer-topeer interactions. British Medical Journal, 328, 1166-1170.

PubMed CrossRef

Joinson, A. N., McKenna, K., Postmes, T., \& Reips, U.-D. (Eds.). (2007). The Oxford handbook of Internet psychology. Oxford: Oxford University Press.

Joinson, A. N., Reips, U.-D., Buchanan, T., \& Paine Schofield, C. (2010). Privacy, trust, and self-disclosure online. Human Computer Interaction, 25, 1-24.

CrossRef

Kraut, R., Olson, J., Banaji, M., Bruckman, A., Cohen, J., \& Couper, M. (2004). Psychological research online: Report of board of scientific affairs' advisory group on the conduct of research on the Internet. American Psychologist, 59, 105-117.

PubMed CrossRef

Mangan, M., \& Reips, U.-D. (2007). Sleep, sex, and the Web: Surveying the difficult-to-reach 
clinical population suffering from sexsomnia. Behavior Research Methods, 39, 233-236.

PubMed CrossRef

Musch, J., \& Reips, U.-D. (2000). A brief history of web experimenting. In M. H. Birnbaum (Ed.), Psychological experiments on the Internet (pp. 61-88). San Diego, CA: Academic Press. CrossRef

Reips, U.-D. (2002). Standards for Internet-based experimenting. Experimental Psychology, 49, 243-256.

\section{PubMed CrossRef}

Reips, U.-D. (2006). Web-based methods. In M. Eid \& E. Diener (Eds.), Handbook of multimethod measurement in psychology (pp. 73-85). Washington, DC: American Psychological Association.

CrossRef

Reips, U.-D. (2007). The methodology of Internet-based experiments. In A. Joinson, K. McKenna, T. Postmes, \& U.-D. Reips (Eds.), The Oxford handbook of Internet psychology (pp. 373-390). Oxford: Oxford University Press.

Reips, U.-D. (2010). Design and formatting in Internet-based research. In S. Gosling \& J. Johnson (Eds.), Advanced Internet methods in the behavioral sciences (pp. 29-43). Washington, DC: American Psychological Association.

Reips, U.-D., \& Birnbaum, M. H. (2011). Behavioral research and data collection via the Internet. In R. W. Proctor \& K.-P. L. Vu (Eds.), The handbook of human factors in web design (2nd ed.). Mahwah, NJ: Erlbaum.

Reips, U.-D., \& Bosnjak, M. (Eds.). (2001). Dimensions of Internet science. Lengerich, Germany: Pabst Science.

Reips, U.-D., \& Garaizar, P. (2011). Mining Twitter: Microblogging as a source for psychological wisdom of the crowds. Behavior Research Methods, 43, 635-642.

PubMed CrossRef

Reips, U.-D., \& Funke, F. (2008). Interval level measurement with visual analogue scales in Internet-based research: VAS Generator. Behavior Research Methods, 40, 699-704.

PubMed CrossRef

Reips, U.-D., \& Lengler, R. (2005). The web experiment list: A web service for the recruitment of participants and archiving of Internet-based experiments. Behavior Research Methods, 37 , 287-292. 
Reips, U.-D., \& Neuhaus, C. (2002). WEXTOR: A web-based tool for generating and visualizing experimental designs and procedures. Behavior Research Methods, Instruments, \& Computers, $34,234-240$.

CrossRef

Schmidt, W. C. (1997). World-Wide Web survey research: Benefits, potential problems, and solutions. Behavioral Research Methods, Instruments, \& Computers, 29, 274-279.

CrossRef

Schmidt, W. C. (2007). Technical considerations when implementing online research. In A. Joinson, K. McKenna, T. Postmes, \& U.-D. Reips (Eds.), The Oxford handbook of Internet psychology (pp. 461-472). Oxford: Oxford University Press.

Stieger, S., \& Reips, U.-D. (2010). What are participants doing while filling in an online questionnaire: A paradata collection tool and an empirical study. Computers in Human Behavior, $26,1488-1495$.

CrossRef

Whitty, M. T., \& Buchanan, T. (2010). “What's in a 'Screen Name'?” Attractiveness of different types of screen names used by online daters. International Journal of Internet Science, 5, 5-19. 